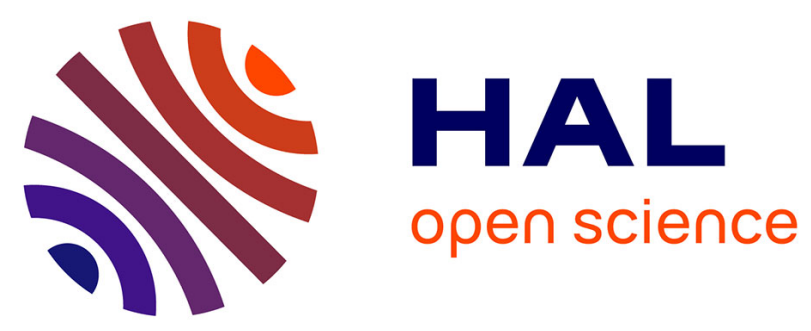

\title{
Rotational Molding of Polyamide-12 Nanocomposites: Modeling of the Viscoelastic Behavior
}

\author{
Mohammadali Shirinbayan, A. Montazeri, M. Nouri Sedeh, Navideh
}

Abbasnezhad, Joseph Fitoussi, Abbas Tcharkhrtchi

\section{- To cite this version:}

Mohammadali Shirinbayan, A. Montazeri, M. Nouri Sedeh, Navideh Abbasnezhad, Joseph Fitoussi, et al.. Rotational Molding of Polyamide-12 Nanocomposites: Modeling of the Viscoelastic Behavior. International Journal of Material Forming, 2021, 14 (1), pp.143-152. 10.1007/s12289-020-01558-9 . hal-03164624

\section{HAL Id: hal-03164624 \\ https://hal.science/hal-03164624}

Submitted on 10 Mar 2021

HAL is a multi-disciplinary open access archive for the deposit and dissemination of scientific research documents, whether they are published or not. The documents may come from teaching and research institutions in France or abroad, or from public or private research centers.
L'archive ouverte pluridisciplinaire HAL, est destinée au dépôt et à la diffusion de documents scientifiques de niveau recherche, publiés ou non, émanant des établissements d'enseignement et de recherche français ou étrangers, des laboratoires publics ou privés. 


\title{
Rotational Molding of Polyamide-12 Nanocomposites: Modeling of the Viscoelastic Behavior
}

\author{
M. Shirinbayan ${ }^{1,2} \cdot$ A. Montazeri ${ }^{3} \cdot$ M. Nouri Sedeh ${ }^{1,3} \cdot$ N. Abbasnezhad ${ }^{1,2} \cdot$ J. Fitoussi $^{1} \cdot$ A. $^{\text {Tcharkhrtchi }}{ }^{1}$
}

\begin{abstract}
Nowadays, polyamide 12 (PA-12) is considered as an interesting polymer in the rotomolding process to manufacture different pieces like the liner part in the storage hydrogen tank (type IV). In this study, the pure polyamide-12 and PA12 pieces, incorporated with $0.5 \%, 1 \%$ and $3 \%$ wt Nano Carbon Black (NCB), were manufactured by the rotomolding process. Different rotomolding parameters such as heating temperature, time of heating, and cooling rate have been optimized to obtain the ideal piece. The effect of volume fraction of NCB in terms of physicochemical and mechanical properties has been studied. Afterward, the optimal volume fraction of $\mathrm{NCB}$ is revealed using different characterization methods. The tensile results specified the addition of NCBs until $0.5 \%$ improved the tensile behavior. The addition of NCBs more than $0.5 \%$ decreases the mechanical properties in terms of failure stress and strain, while it has no significant effect on the elastic modulus of PA-12. The bi-parabolic the Perez model has been used to study the viscoelastic behavior of PA-12 using the Cole-Cole method. The constants of the Perez model indicate a good correlation between viscoelastic experimental results and the model used.
\end{abstract}

Keywords Polyamide- $12 \cdot$ Rotomolding $\cdot$ Nano carbon black $\cdot$ Viscoelastic

\section{Introduction}

Rotational molding is a pressure-free process. It provides the ability to produce hollow plastic containers with different, homogenate dimensions, with no material wastage and no weld line. This process comprises four steps: charging of the polymer; heating of the mold in an oven to processing temperatures with simultaneous rotation in two axes. As heated, the polymer adheres to the mold and becomes fused. The next steps are cooling of the mold by air or a water spray and unloading of a produced item from the mold $[1,2]$.

M. Shirinbayan

mohammadali.shirinbayan@ensam.eu

A. Montazeri

a.montazeri@guilan.ac.ir

M. Nouri Sedeh

mohsen.nouri_sedeh@ensam.eu

N. Abbasnezhad

navideh.abbasnezhad@ensam.eu

J. Fitoussi

joseph.fitoussi@ensam.eu
Numerous additives, like inorganic fillers, for improving the mechanical properties of the material can be added [3-8]. However, the addition of inorganic fillers increases the viscosity, which results in not a good distribution of the fillers and an increase of porosity [9-11]. Moreover, enough toughness of the material is needed to permit extraction from the molds. This technology, however, contains serious limitations to produce complex geometries [12]. One of the problems in rotomolding is bubbles of gasses trapped during the sintering of the powders, which reduce the mechanical strength of the produced piece [13-15].

\author{
A. Tcharkhrtchi \\ abbas.tcharkhtchi@ensam.eu \\ 1 Arts et Metiers Institute of Technology, CNAM, LIFSE, HESAM \\ University, F-75013 Paris, France \\ 2 Arts et Metiers Institute of Technology, CNAM, PIMM, HESAM \\ University, F-75013 Paris, France \\ 3 Faculty of Engineering, Department of Nanotechnology, University \\ of Guilan, Rasht, Iran
}


The temperature of the air inside the mold gives an idea quite precise about the changes in the state of the polymer, especially when it starts melting when all the powder is melted, and when it starts to crystallize and when the crystallization is finished [16-20].

More than $85 \%$ of the publications wherein the manufacturing method is rotational molding choose Polyethylene (PE) [21-23]; however, using other polymers is an interesting matter. A special PA11 powder (Rilsan ${ }^{\circledR}$ Roto 11) grade was used for rotational molding [24]. It is particularly appropriate for the molding of tanks and vessels requiring chemical resistance such as fuel, hydraulic fluids, corrosive liquids, coolant mixtures, and tremendous barrier properties. Besides, it poses excellent dimensional stability at high-temperature and impact resistance at low temperature. Like PA-11, polyamide 12 with the abbreviation of PA-12 is a family of polyamides [25-28]. PA-12 polymers are known for their different performance properties $[29,30]$. Some performance properties of this type of polyamide are simple to process in typical equipment (extrusion, injection molding, etc.), gas impermeability, lightweight-enhance fuel economy, excellent noise dampening, very good chemical resistance, low water absorption (much better dimensional stability than lower polyamides (PA-6 or PA-66 for example)), good impact properties and flexibility, especially at lower temperatures, outstanding abrasion resistance, and tremendous resistance to stress cracking.

The temperature of the polymer and mold depends on the oven, but they also depend on other reasons such as [31]:

- Quantity and nature of the polymer.

- Surface/volume ratio of the mold.

- The material of the mold and its thickness.

Nowadays nanotechnology received increasing attention due to its mechanical properties including strength, modulus, and dimensional stability and also thermal stability, chemical resistance, and electrical conductivity. Nanoparticles and supercritical technology combination have an extraordinary potential to produce a novel class of materials that are state-ofthe-art, relatively weightless, high strength and multifunctional. A few amounts of well-dispersed nanoparticles in the polymer may affect bypassing micro-particles to nanoparticles a change in physical properties and an increase in the ratio of surface area to volume [32-34].

The most common representation of nanoparticles is black carbon, or carbon black. It has been massively produced for decades and used in car tires to increase their lifespan. The cause of black color in the tire is the presence of this black additive.

Therefore, this paper is aimed towards the rotational molding of PA-12, reinforced with $0.5 \%, 1 \%$ and $3 \%$ wt Nano Carbon Black (NCB). Firstly, rotomolding parameters of PA-12, such as oven temperature, heating, and cooling times have been optimized. These optimal parameters have been applied for different PA-12, reinforced with $0.5 \%, 1 \%$, and $3 \%$ wt Nano Carbon Black (NCB). Then, the physicochemical and mechanical properties of the final pieces have been characterized. Finally, bi-parabolic Perez model has been used to study the viscoelastic behavior using the Cole-Cole method.

\section{Materials description, processing, and methods}

\section{Materials}

\section{Polyamide 12 (PA-12)}

Semi-crystalline Polyamide 12 used in this study was PA-12, in the form of powder, supplied by ARKEMA Revolve with a density of $1.01 \mathrm{~g} / \mathrm{cm}^{3}$.

\section{Nano carbon black (NCB)}

The nanopowders used in this study were provided by Plasmachem GmbH D-12489 Berlin, Germany, typeCB13 with an average particle size of $13 \mathrm{~nm}$, bulk density of $0.1 \mathrm{~g} /$ $\mathrm{cm}^{3}$ and specific surface area (BET) of $570 \pm 20 \mathrm{~m}^{2} / \mathrm{g}$.

\section{Rotational molding process}

The rotational molding machine "LAB 40" (Fig. 1), of Shuttle type built by STP and available in the PIMM laboratory, has employed in this work. This machine is equipped with a human-machine interface (HMI) to set easily its operating parameters, namely: the oven temperature, the two rotational speeds, and the heating and finally cooling times. In this machine, the cooling process has been achieved by air.

PA-12 and NCBs were mixed completely before processing by shaking in a glass flask for $30 \mathrm{~min}$. PA-12 powders were initially dried in a vacuum oven at $80^{\circ} \mathrm{C}$ for $4 \mathrm{~h}$ before the rotomolding process. After that, the required amount of polyamide $(250 \mathrm{~g})$, in powder form, is introduced into the mold's cavity (Fig. 2). This mold is then closed and is situated in the furnace. During the heating phase, the mold slowly rotates on two axes (major axis $3.6 \mathrm{rpm}$ and minor axis $9.6 \mathrm{rpm})$. The heat transfer cause is melting the polymer powder. This molten material almost uniformly covers all the inner walls of the mold. The temperature of the molten material attained is well more than the melting point.

After that, the mold is moved to the cooling station. The need for cooling is important and clearly, rapid cooling is desirable for economic reasons, but this can cause problems such as warping. In the last step, the rotation of the mold is stopped; the mold is removed from the machine and is then 
Fig. 1 Rotational molding machine LAB 40

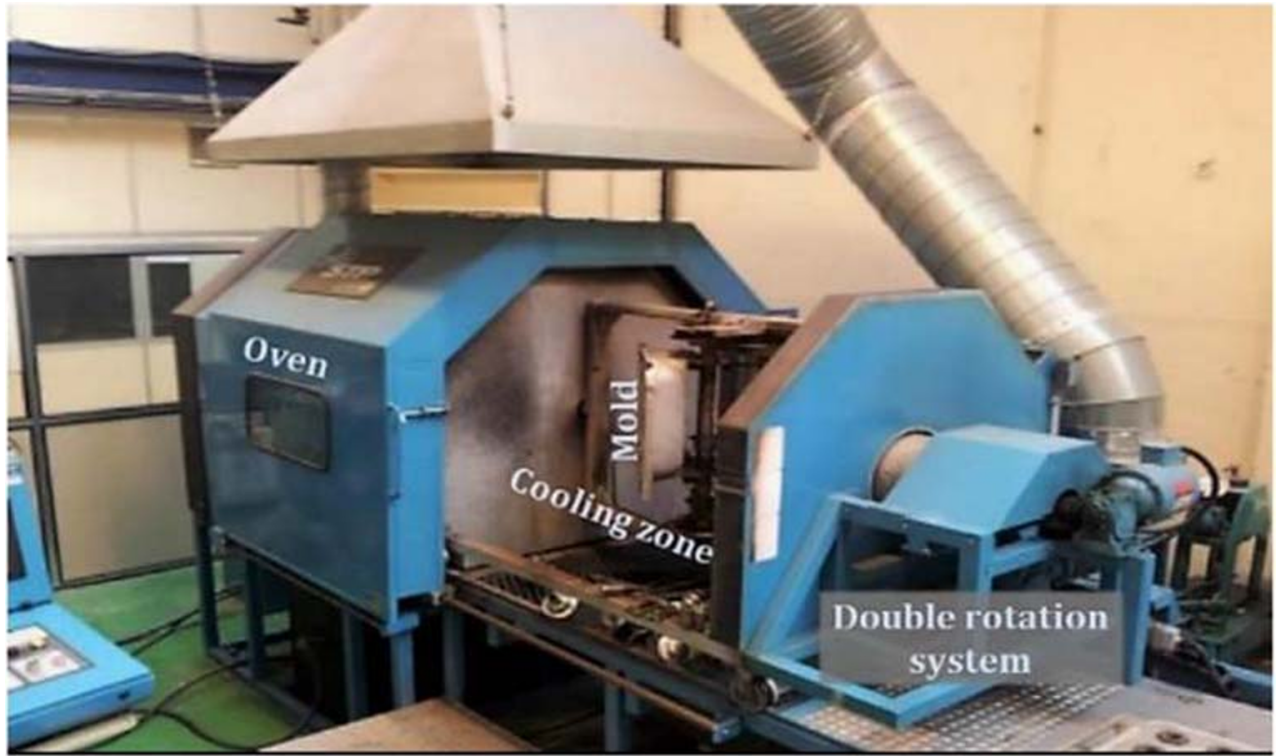

opened, and the manufactured part is demolded. The mold is so then available for a new cycle.

\section{Characterization methods}

\section{Differential scanning Calorimetry (DSC)}

DSC Q10 V9.0 was utilized to find out the temperature evolution near the glass transition temperature up to the melting point. The sample used (from rotomolded parts), was $5.8 \mathrm{mg}$, which was first heated from 0 to $200{ }^{\circ} \mathrm{C}$, then cooled to $0{ }^{\circ} \mathrm{C}$, with a rate of $5{ }^{\circ} \mathrm{C} / \mathrm{min}$.

\section{Dynamic thermos-mechanical analysis (DMTA)}

DMTA testing was performed using a Q800 V21.2 Dynamic Mechanical Analyzer. Rectangular PA-12 specimens with approximate dimensions of $25 \times 4 \times 3 \mathrm{~mm}^{3}$ were tested over the entire temperature range of the DMTA instrument from $30{ }^{\circ} \mathrm{C}$ to $100{ }^{\circ} \mathrm{C}$ at different frequencies of $0.5 \mathrm{~Hz}, 1 \mathrm{~Hz}, 5 \mathrm{~Hz}, 10 \mathrm{~Hz}$, and $50 \mathrm{~Hz}$ with a constant amplitude of $30 \mathrm{~N}$. The storage and loss moduli were measured versus temperature. After that, the corresponding parameter was determined.

Fig. 2 Mold used in this study

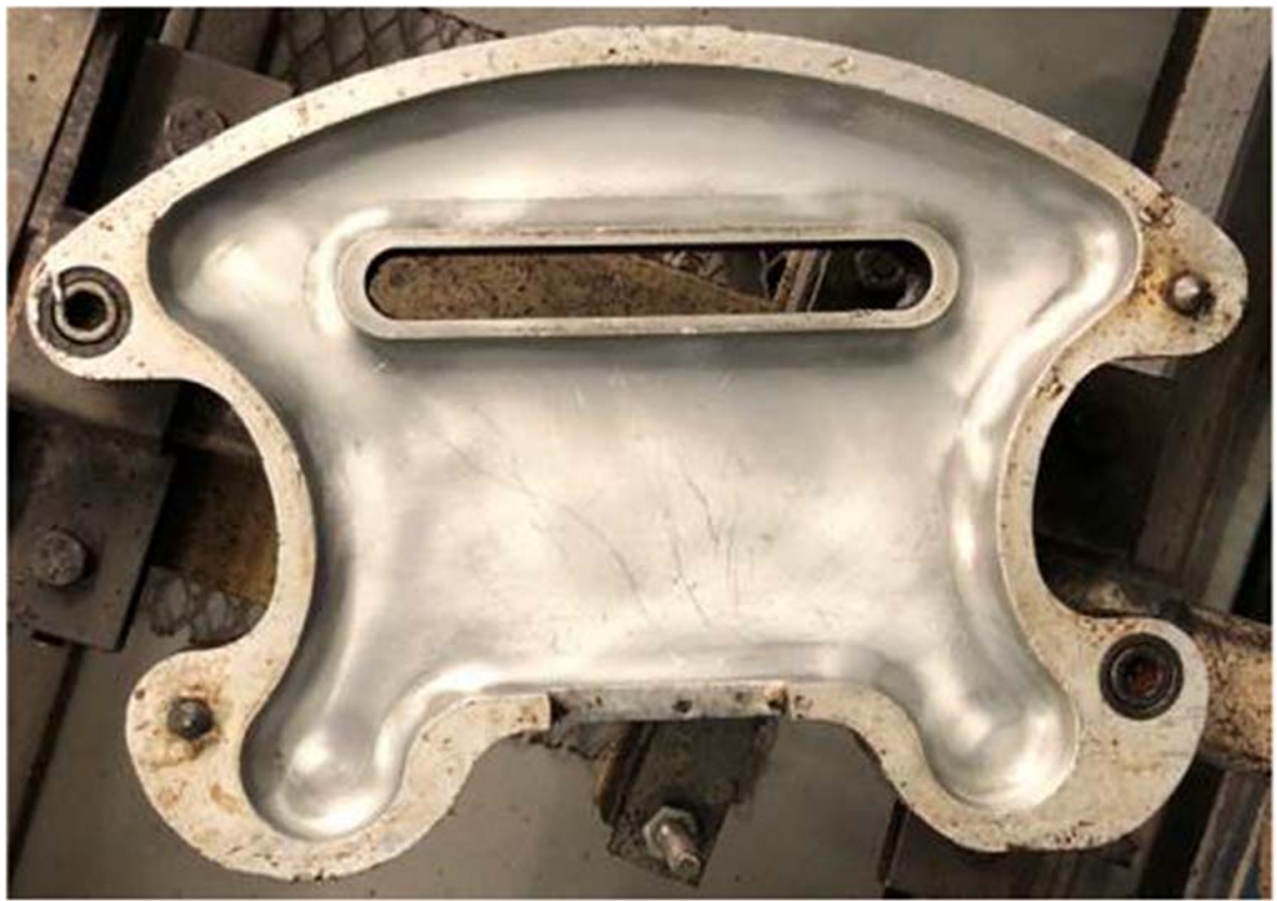




\section{Microscopic observations}

Scanning Electronic Microscope (HITACHI 4800 SEM), was utilized to examine the material microstructure qualitatively.

\section{Tensile test}

Quasi-static tensile tests were carried out using the specimen dimension (ISO-527-2-5A) with a thickness of $3 \mathrm{~mm}$ at $25^{\circ} \mathrm{C}$. Tensile tests were performed until the polymer specimen failure using Instron 5881 machine with a velocity of $2 \mathrm{~mm} / \mathrm{min}$. Each test has been repeated five times.

\section{Experimental results and discussion}

\section{DSC analysis}

DSC was used to investigate the response of PA-12 at temperature variations. The result presented in Fig. 3 shows PA-12 pure has a melting temperature of $177^{\circ} \mathrm{C}$ and a crystallization temperature of about $147^{\circ} \mathrm{C}$.

According to this result, the glass transition temperature of PA-12 is about $53{ }^{\circ} \mathrm{C}$. One can note that there is no significant difference in glass transition, melting and crystallization temperatures of pure PA-12 and PA-12, reinforced with $0.5 \%$ and $1 \%$ wt Nano Carbon Black (NCB). In principle, the charged particles are of the nucleating agent. They can modify the morphology of the crystalline phase. DSC results confirm that the degree of crystallization is slightly increased by adding the NBCs which can be improved the mechanical properties. The values of the crystallinity degree for pure PA-12 and PA-12, reinforced with $0.5 \%$ and $1 \%$ wt Nano Carbon Black (NCB) are $21.5,22.5$, and $23 \%$, respectively. The later shows that the degree of crystallization is slightly increased by adding the NBCs because of an increase in the nucleation site which can be improved the mechanical properties (Table 1).

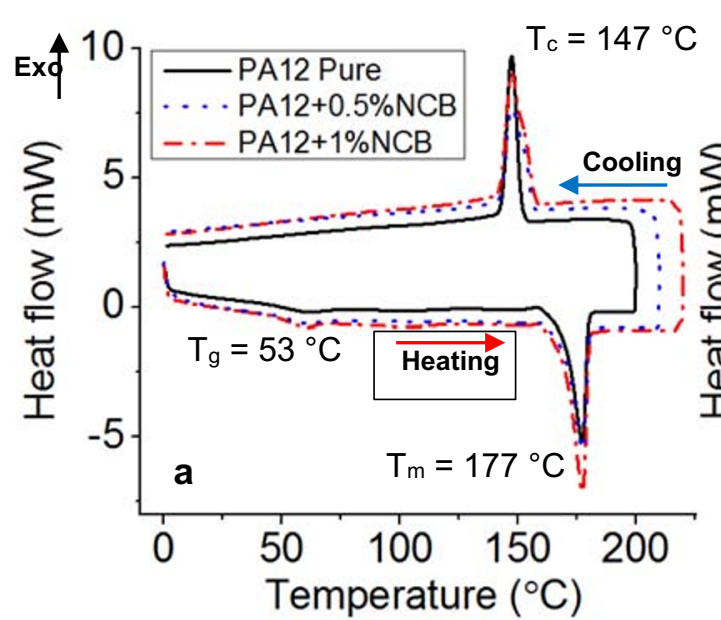

Table 1 The values of $\mathrm{T}_{\mathrm{g}}, \mathrm{T}_{\mathrm{m}}, \mathrm{T}_{\mathrm{c}}$ and $\mathrm{X}_{\mathrm{c}}$ for pure PA-12, PA-12 with $0.5 \%$ and $1 \%$ of NCBs

\begin{tabular}{lllll}
\hline Sample & $\mathrm{T}_{\mathrm{g}}\left({ }^{\circ} \mathrm{C}\right)$ & $\mathrm{T}_{\mathrm{m}}\left({ }^{\circ} \mathrm{C}\right)$ & $\mathrm{T}_{\mathrm{c}}\left({ }^{\circ} \mathrm{C}\right)$ & $\mathrm{X}_{\mathrm{C}}$ \\
\hline Pure PA-12 & 53 & 177 & 147 & 21.5 \\
PA-12 with 0.5\% of NCBs & 53 & 177 & 147 & 22.5 \\
PA-12 with 1\% of NCBs & 53 & 177 & 147 & 23 \\
\hline
\end{tabular}

\section{DMTA measurement}

DMTA test is preferentially performed to study the different transitions temperatures. In this work, DMTA tests have performed according to the alternating frequencies configuration in the temperature range between $30^{\circ} \mathrm{C}$ and $70{ }^{\circ} \mathrm{C}$. DMTA results (Fig. 4) show that the value of glass transition temperature according to the peak of $\tan \delta$ is equal to $53{ }^{\circ} \mathrm{C}$. This value is related to $T_{\alpha}$ which is the mechanical temperature transition associated with $\mathrm{T}_{\mathrm{g}}$. $\mathrm{T}_{\alpha}$ depends on the angular frequency. This value is like the value obtained by DSC analysis.

\section{Choice of some parameters of the process}

When the oven temperature is not high enough, the time required to reach the melting point $\left(\mathrm{T}_{\mathrm{m}}\right)$ of the polymer becomes important. In this case, if the overall time chosen for a cycle is insufficient, so then the material will not be completely melted and which causes malformations of the rotationally molded part and various imperfections: low strength, stiffness, and ductility. Conversely, if the polymer overheats at a temperature above the degradation temperature $\left(\mathrm{T}_{\mathrm{D}}\right)$, degradation processes will occur, and the part will be of poor quality.

To better controlling the temperature variation of the polymer or internal mold air over time, the best way is to use the Datapaq ${ }^{\circledR}$ Tracker Telemetry system that tracks variation of this temperature. In fact, by recording this temperature, it is possible to observe the changes in the state of the polymer

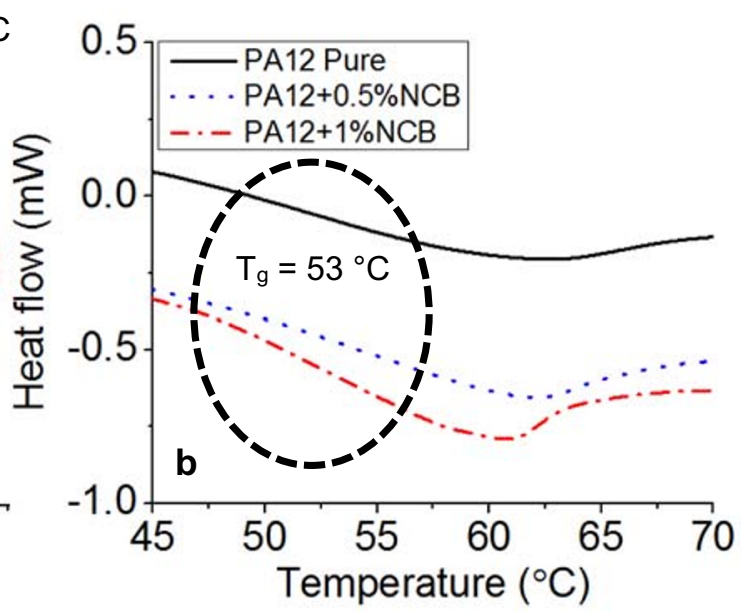

Fig. 3 (a) DSC results of PA12, PA12-0.5\% NCB and PA12-1\% NCB and (b) zoom of $\mathrm{T}_{\mathrm{g}}$ zone 


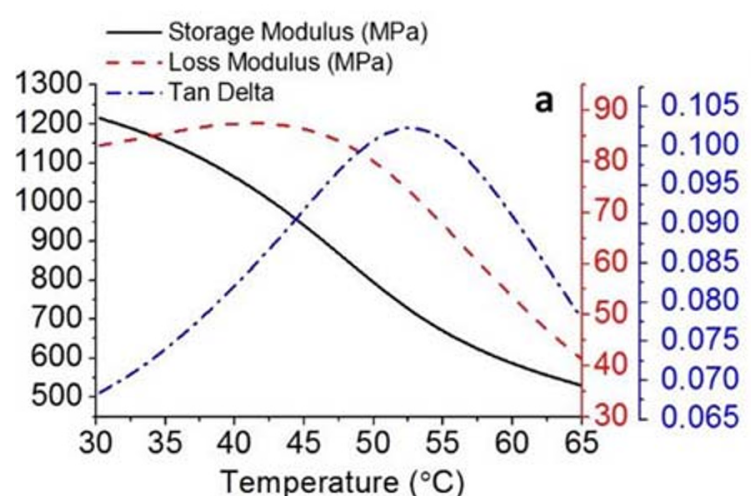

Fig. 4 DMTA curve of (a) PA-12 and (b) PA-12 with $0.5 \%$ of NCB

during the process in real-time. One can note the method of cooling the mold, following the heating phase, can have a significant effect on the quality of the part.

After several attempts, using DSC and DMTA analysis, the values of three important parameters for the rotational molding process chosen in this study are given below:

- Oven temperatures: $280^{\circ} \mathrm{C}$

- Heating times: $15 \mathrm{~min}$.

- Cooling rate: by blown air

In the beginning, the mold and the polymer are at room temperature. The heating process is in a way that, first the mold absorbs heat and then it goes through the polymer powders. On condition that the polymer does not melt, the temperature inside the mold increases in a steady state.

Close to the melting point (near $147^{\circ} \mathrm{C}$ ), the coalescence of the first layer of powder occurs and the first molten layer of the polymer, adheres to the mold. After that, the following layers will be formed in the same way on the first layer. One can see that the slip of temperature around $175{ }^{\circ} \mathrm{C}$ decreases. This decrease can be explained by energy absorption due to the latent heat of fusion. From this point, the material continues melting, under the effect of rotation.

Afterward, all the powder is melted and regains its increasing slip, while the melted materials are homogenizing. The maximum temperature of polymer $\left(220^{\circ} \mathrm{C}\right)$ is chosen to give enough time and fluidity to the polymer for a homogeneous distribution. Here, the best-chosen temperature is very important because the degradation of the polymer should be considered. Since the curve starts to decrease, the homogenization of the molten polymer takes place. Due to the absence of pressure in the rotomolding process, some bubbles will trap between the particles, to eliminate these bubbles which affect the final product properties; the homogenization period should be adequate so that the trapped air gradually disappears. Near to 24 min after starting the rotomolding process, one can observe the polymer begins to solidify. In the case of

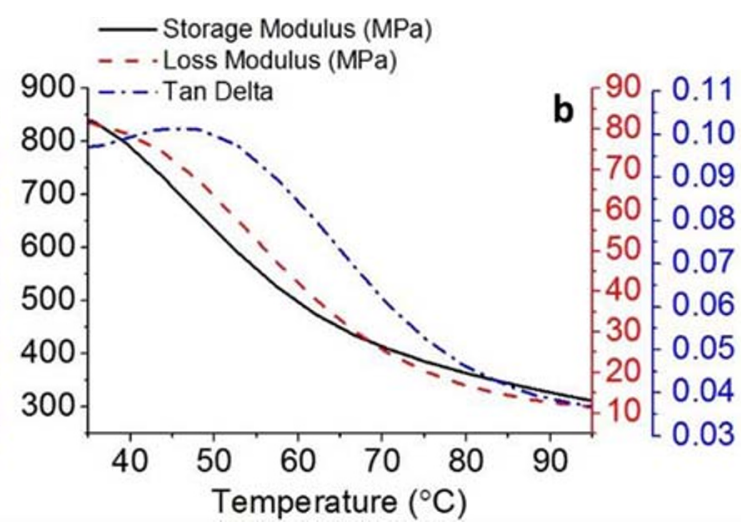

semi-crystalline polymers, this point is close to the crystallization temperature of the polymer. From this point, the speed of the temperature drops under the exothermic effect of crystallization. After $35 \mathrm{~min}$ of cooling stage the piece is completely crystallized and can be taken off from the mold (shown in Fig. 5).

\section{Macro and microstructural analysis}

In the macroscopic view, one can see the good quality of finished pieces (Fig. 6). This confirms the chosen parameters of the rotomolding process in a macroscopic view. However, the quality of the pieces should be confirmed by other's analysis. One can note that by increasing the percentage of NCBs, in the macroscopic view there is no difference. Because of this in Fig. 6 macroscopic views of pure PA-12 and PA-12 with $0.5 \%$ of NCBs are presented.

For microstructural characterization, samples after polishing were analyzed with scanning electron microscopy (SEM). Figure 7 shows SEM micrograph of pure PA-12, PA12 with $0.5 \%$ of NCB, PA- 12 with $1 \%$ of NCB and PA-12 with $3 \%$ of $\mathrm{NCB}$.

One can note that by increasing the percentage of NCBs until $0.5 \%$ the microstructure doesn't change; nevertheless, for $1 \%$ and $3 \% \mathrm{NCBs}$, the porosity has obviously appeared. One can note that to analyze the degree of porosity the software of ImageJ has been used to measure the size of porosities. It has been verified that the photos presented in Fig. 7 can be the representative microstructure of final pieces for all conditions. The results confirm that the size of porosities in the case of $3 \%$ NCBs is about 1.5 times bigger than that of $1 \%$ NCBs.

\section{Tensile behavior}

Microstructures of the final pieces showed the presence of porosity for the $1 \%$ and $3 \%$ of NCBs. To analyze the mechanical behavior of the pieces, tensile tests were performed. Stress-strain $(\sigma-\varepsilon)$ curves plotted for pure PA-12, PA12- 
Fig. 5 Temperature evaluation during rotomolding process of pure PA-12

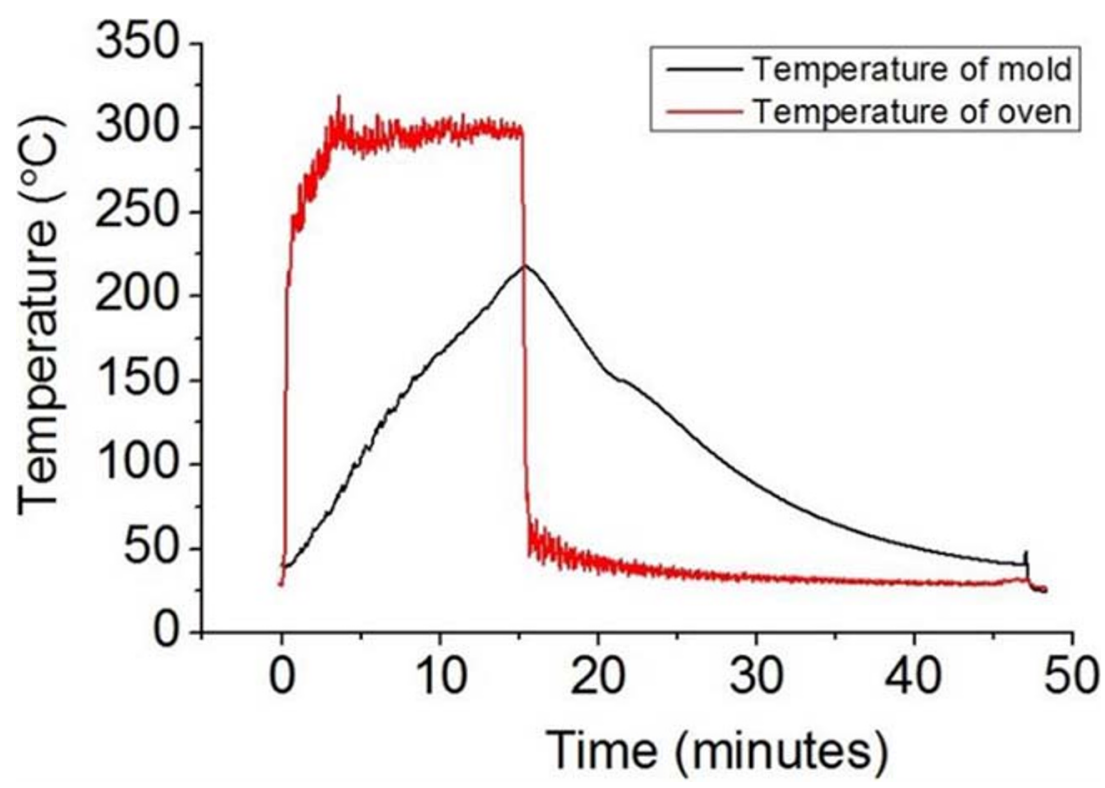

0.5\% NCBs, PA12-1\% NCBs and PA12-3\% NCBs in Fig. 8. For each percentage, five samples were tested, and the stressstrain curves obtained for each sample have remarked that there is good repeatability of tensile behavior.

Tensile curves in Fig. 8 and Table 2 indicate that the overall behavior of pure PA-12 was influenced by adding NCBs more than $0.5 \%$ of NCB. For $0.5 \%$ of NCB maximum stress reaches around $55 \mathrm{MPa}$; however, for $3 \%$ of NCBs, its value decreases to $20 \mathrm{MPa}$. One can note that by increasing the percentage of NCBs, the porosities are increased which confirms the reduction of mechanical properties.

\section{Modeling}

\section{WLF equation: Free volume fraction calculation}

To explore the effect of temperature on viscoelastic properties of PA-12 with $0.5 \%$ of NCBs, multi- frequencies DMTA test was conducted on specimens in flexion mode and the results are shown in Fig. 9. By increasing the frequency, the $\alpha$-transition temperature, $\mathrm{T}_{\alpha}$ (related to $\mathrm{T}_{\mathrm{g}}$ ) has an increasing trend to high temperatures.

As mentioned, the viscoelastic behavior of the polymer is related to the frequency of applied loading. This dependence between temperature and viscosity which is proportional to frequency may be explained by Williams-Landel-Ferry (WLF) equation:

$\frac{1}{\log \frac{\mathrm{f}}{\mathrm{f}_{\mathrm{r}}}}=\frac{C_{2}}{C_{1}}\left(\frac{1}{T-T_{g}}\right)+\frac{1}{C_{1}}$

Where $\mathrm{f}=$ frequency, $\mathrm{T}=$ temperature, $\mathrm{f}_{\mathrm{r}}=$ reference frequency $(0.5 \mathrm{~Hz}), \mathrm{T}_{\mathrm{r}}=$ reference temperature. $\mathrm{C}_{1}=\frac{\mathrm{B}}{\mathrm{f}_{\mathrm{g}}}$ and $\mathrm{C}_{2}$ $=\frac{\mathrm{f}_{\mathrm{g}}}{\Delta \alpha}$.
Fig. 6 Macroscopic view of (a) pure PA-12 and (b) PA-12 with $0.5 \%$ of $\mathrm{NCB}$
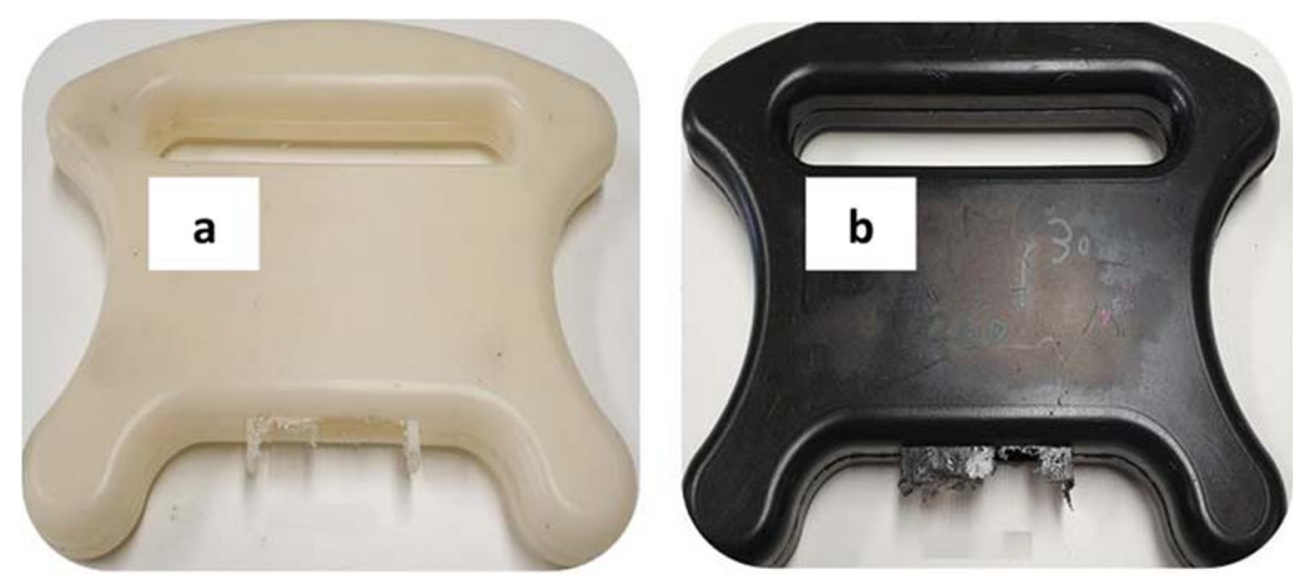
Fig. 7 SEM micrograph of (a) pure PA-12, (b) PA-12 with $0.5 \%$ of NCBs, (c) PA-12 with $1 \%$ of NCBs, (d) PA-12 with $3 \%$ of NCBs, (e) zoom of porosity on c and (f) zoom of porosity on $d$
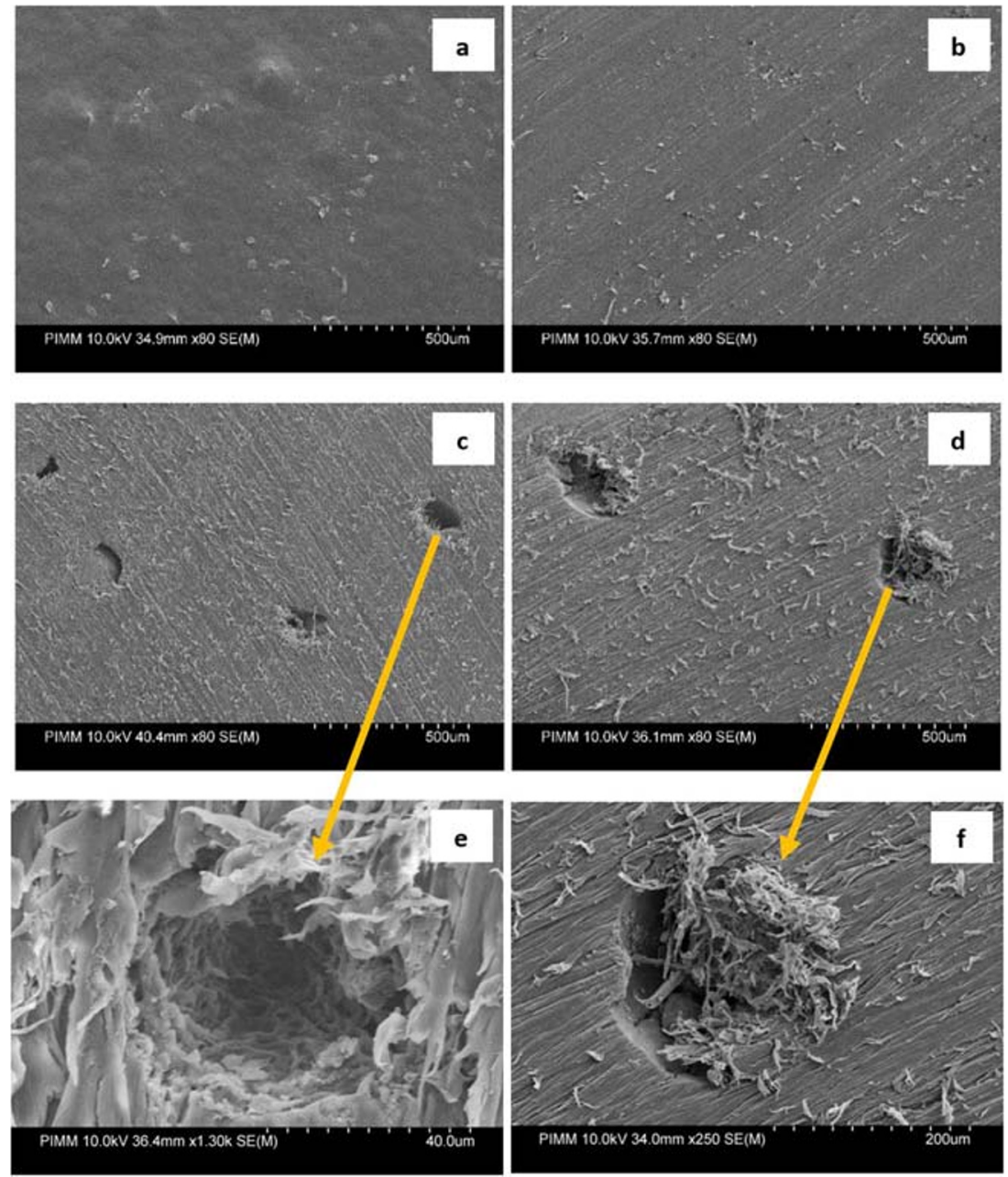

While $\mathrm{B}$ is constant near to $1, \Delta \alpha=$ thermal expansion coefficient obtained by un dilatometer $\left(1.1 \times 10^{-4}\right)$ and $f_{g}=$ free volume fraction.

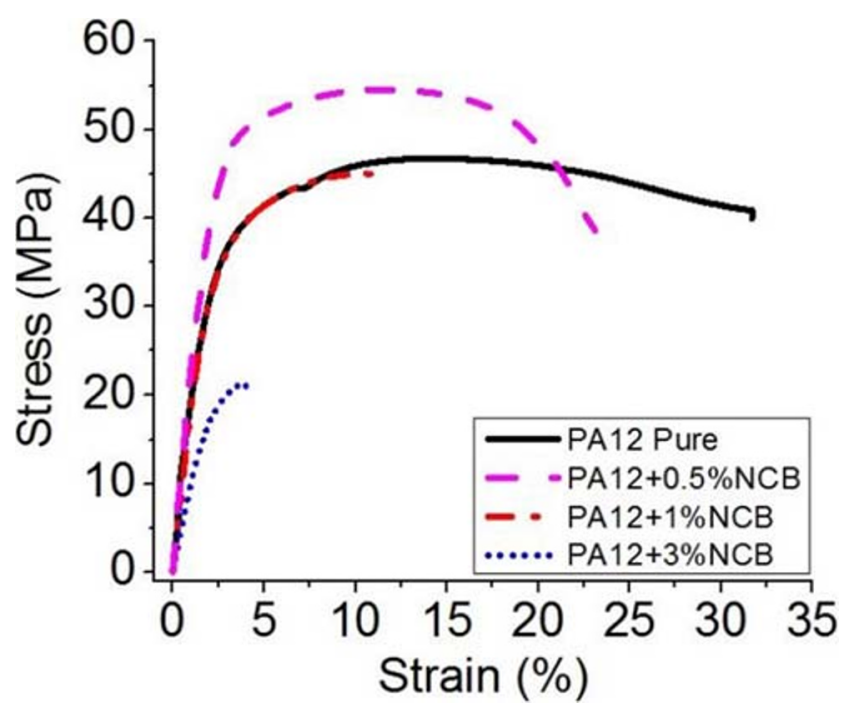

For verifying the validity of this equation, the linear regression method is utilized and $\frac{1}{\log _{\frac{f}{f_{r}}}}$ is plotted versus $\frac{1}{\left(T-T_{\mathrm{r}}\right)}$. If this plot is linear having $\mathrm{A}=\frac{\mathrm{C}_{2}}{\mathrm{C}_{1}}$ as slope, then the validity of the WLF equation is validated. Figure 10 shows the result of linear regression. Therefore, in this temperature range, it can be considered that, PA- 12 with $0.5 \%$ of NCBs follows the WLF equation. Therefore, the value of free volume fraction coefficient for PA-12 with $0.5 \%$ of NCBs by using $(f g=\sqrt{B \times \Delta \alpha \times A})$ is determined by about $1.94 \times 10^{-2}$. The value of $\mathrm{C}_{1}, \mathrm{C}_{2}, \mathrm{f}_{\mathrm{g}}$, and $\Delta \alpha$ are shown in Table 3. The WLF coefficients $C_{1}$ and $C_{2}$

Table 2 The values of E, $\sigma$ and $\varepsilon$ for pure PA-12, PA- 12 with $0.5 \%, 1 \%$, and $3 \%$ of $\mathrm{NCBs}$

\begin{tabular}{llll}
\hline Sample & E (GPa) & $\sigma_{\max }(\mathrm{MPa})$ & $\varepsilon_{\max }(\%)$ \\
\hline Pure PA-12 & 2 & 46 & 32 \\
PA-12 with $0.5 \%$ of NCBs & 2 & 55 & 24 \\
PA-12 with 1\% of NCBs & 2 & 45 & 12 \\
PA-12 with 3\% of NCBs & 1.6 & 20 & 4 \\
\hline
\end{tabular}

Fig. 8 Representative curves of tensile test of neat PA12 
Fig. 9 Multi-frequencies DMTA curve of PA-12 with $0.5 \%$ of NCBs: (a) storage modulus versus $\mathrm{T}$ and (b) loss modulus versus $\mathrm{T}$
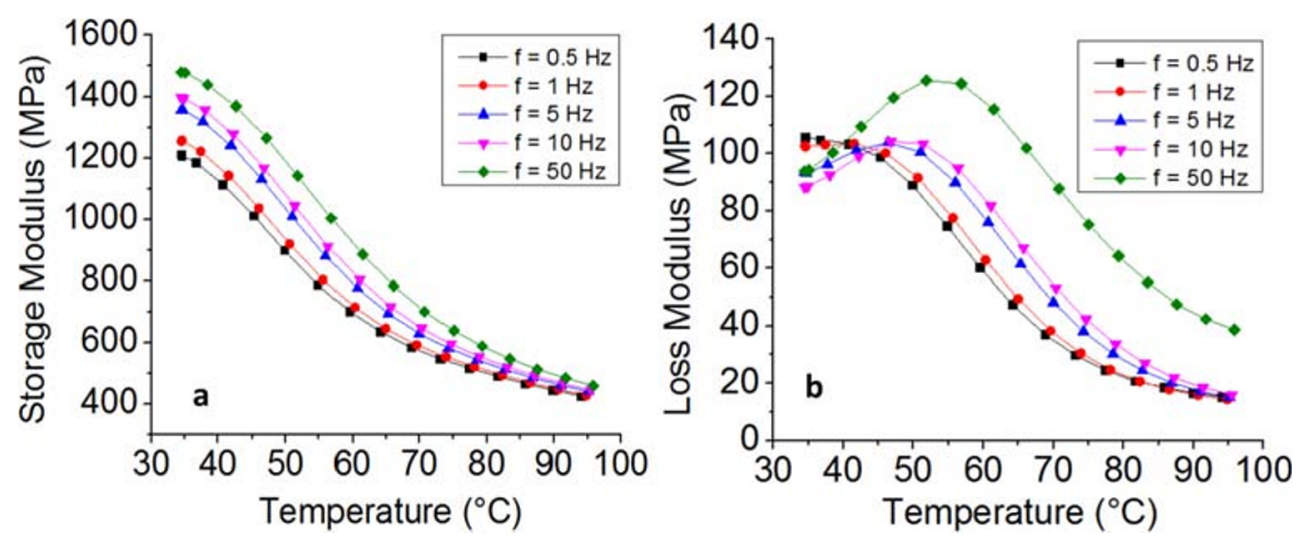

appear to be intercorrelated $\mathrm{C}_{2} / \mathrm{C}_{1}=3.4$, which is confirmed by literature data on epoxy/carbon nanotubes network [35].

\section{Cole-Cole diagram}

Different approaches have been used to study the viscoelastic properties in the temperature range between the glassy and rubbery domain, and different models have been proposed to predict these properties. These models generally represent the curve of E" (loss modulus) versus E' (storage modulus) and the curve is called the Cole-Cole diagram. For the validation of the theoretical model experimental data obtained by the dynamic mechanical thermal analysis (DMTA) tests are needed. After DMTA tests, an asymmetric Cole-Cole diagram has been plotted (Fig. 11). According to the Perez model, the behavior of polymers can be explained by the bi-parabolic model presented by the following equation:

$E^{*}=E_{0}+\frac{E_{\infty}-E_{0}}{1+(i \omega \tau)^{\kappa}+Q(i \omega \tau)^{\kappa^{\prime}}}=E^{\prime}+i E^{\prime \prime}$

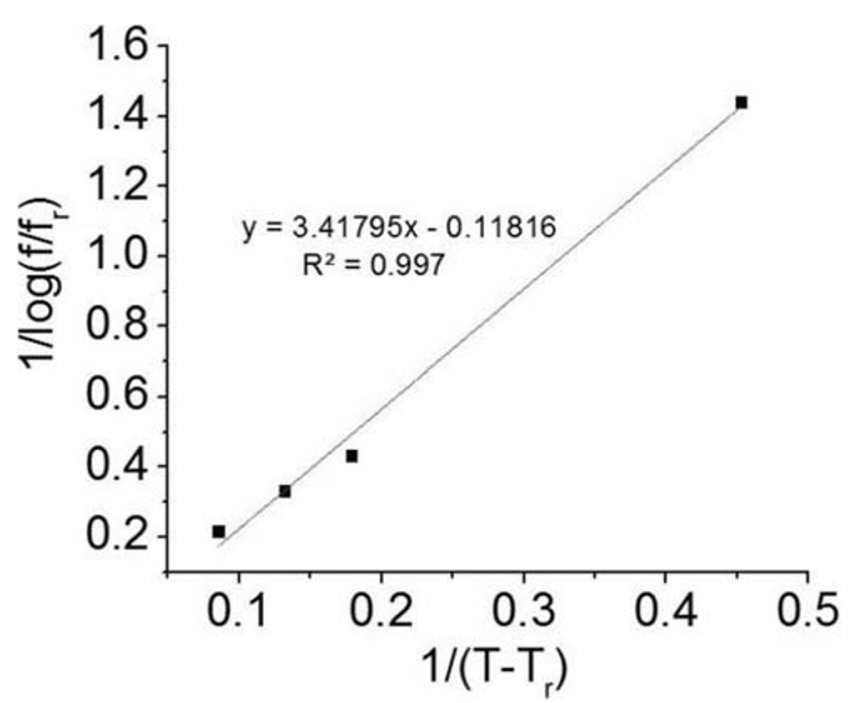

Fig. 10 Linear regression of WLF equation on the results obtained from DMTA test
With

$$
E^{\prime}=E_{0}+\left(E_{\infty}-E_{0}\right) \frac{1+\cos \left(\frac{k \pi}{2}\right)(\omega \tau)^{-K}+Q \cos \left(\frac{k^{\prime} \pi}{2}\right)(\omega \tau)^{-K^{\prime}}}{D}
$$

$E^{\prime \prime}=\left(E_{\infty}-E_{0}\right) \frac{\sin \left(\frac{k \pi}{2}\right)(\omega \tau)^{-K}+Q \sin \left(\frac{k^{\prime} \pi}{2}\right)(\omega \tau)^{-K^{\prime}}}{D}$

and

$$
\begin{aligned}
D= & {\left[1+\cos \left(\frac{k \pi}{2}\right)(\omega \tau)^{-K}+Q \cos \left(\frac{k^{\prime} \pi}{2}\right)(\omega \tau)^{-K^{\prime}}\right]^{C^{\prime}} } \\
& +\left[\sin \left(\frac{k \pi}{2}\right)(\omega \tau)^{-K}+Q \sin \left(\frac{k^{\prime} \pi}{2}\right)(\omega \tau)^{-K^{\prime}}\right]^{C^{\prime}}
\end{aligned}
$$

Where $\mathrm{k}$ and $\mathrm{k}^{\prime}$ and $\mathrm{Q}$ are the constants of this model. $\omega=$ $2 \pi \mathrm{f}$ is the angular frequency ( $\mathrm{f}=$ frequency) and $\mathrm{E}^{*}$ is the complex shear modulus: $\mathrm{E}_{\infty}$ and $\mathrm{E}_{0}$ are the value of shear modulus at the respectively glassy and rubbery states. $\mathrm{k}$ and $\mathrm{k}^{\prime}$ depend on the slope of the tangents at the beginning and the end of the Cole-Cole diagram, $\mathrm{Q}$ is a constant related to the maximum value of $E " . \tau$ is the average relaxation time.

A numerical method allows the plotting of the theoretical Cole-Cole diagram to fit it on the experimental curve. The result of modeling is shown in Fig. 11 and Table 4. The theoretical curve fits perfectly with the experimental results, signifying that the bi-parabolic model can accurately predict the viscoelastic behavior of PA-12 and PA-12 with $0.5 \%$ of NCB.

Table 3 The values of WLF constants

\begin{tabular}{llll}
\hline $\mathrm{C}_{1}$ & $\mathrm{C}_{2}$ & $\Delta \alpha$ & $\mathrm{f}_{\mathrm{g}}$ \\
\hline 15.1 & 51.6 & $1.1 \times 10^{-4}$ & $1.94 \times 10^{-2}$ \\
\hline
\end{tabular}




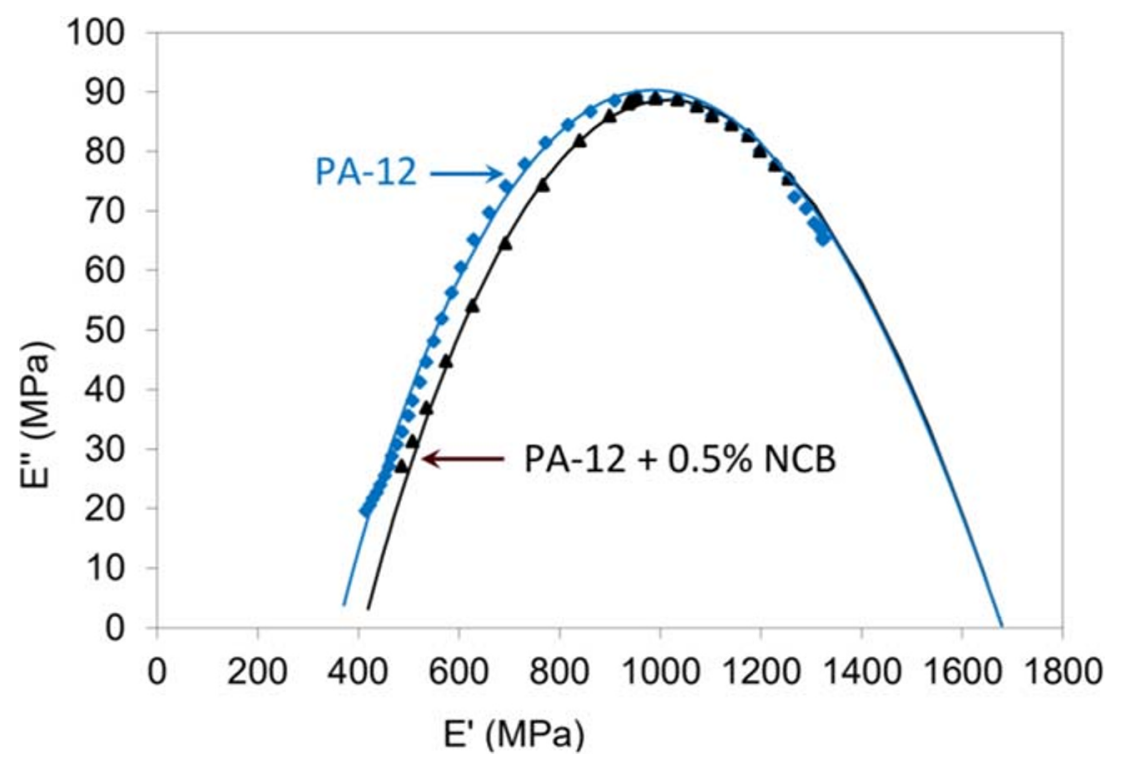

The parameter $\mathrm{k}$ shows molecular motion and the intensity of the effects of correlation involved during the expansion of the Somigliana dislocation (smd) [36]. The values of $\mathrm{k}$ for PA12 and PA- 12 with $0.5 \%$ of NCB are similar while an increase in the value of $\mathrm{k}$ indicates weaker molecular motion. The parameter Q is associated with the maximum value of $\mathrm{E}$ " which increases with increasing the value of $Q$. An increase in the value of $\mathrm{Q}$ is shown with the addition of $0.5 \%$ of $\mathrm{NCB}$ to the PA12. With the rise in the value of $\mathrm{Q}$, the loss modulus increases, and an improvement is observed in the damping properties. The values of $\mathrm{E}^{\infty}$ indicate slight enhancement in the elastic properties by adding the $0.5 \%$ of NBCs.

The parameter $\mathrm{k}^{\prime}$ accounts for the difficulty with which local shearing occurs and it is the most important parameter in the Perez model. When $\mathrm{k}^{\prime}$ decreases, the movement of polymer chains becomes slower. As soon as a local shearing occurs, the molecular orientation resulting from it makes molecular movement more complicated. The addition of $0.5 \%$ of NCBs to the PA12 did not affect the values of $\mathrm{k}^{\prime}$. In other words, in $\alpha$ region, local shearing occurs easily and $\mathrm{T}_{\mathrm{g}}$ has not changed according to DMA results presented in Fig. 4. Montazeri has investigated the viscoelastic behavior of epoxy/ carbon nanotubes by plotting the Cole-Cole diagram using the results of DMTA test. There was a good agreement between the Perez model and the viscoelastic behavior of the composite specimen [37].

Table 4 The values of Cole-Cole constants

\begin{tabular}{cllllll}
\hline Material & $\mathrm{k}$ & $\mathrm{k}^{\prime}$ & $\mathrm{Q}$ & $\mathrm{E}^{0}$ & $\mathrm{E}^{\infty}$ & $\tau$ \\
\hline PA-12 & 0.15 & 0.23 & 0.40 & 360 & 1680 & 0.2 \\
PA-12+ 0.5\% of NCB & 0.15 & 0.23 & 0.55 & 410 & 1690 & 0.2 \\
\hline
\end{tabular}

\section{Conclusion}

The main aim of this paper is to open the discussion about Polyamide-12 properties by adding three percentages of Nanoparticles of Carbon Black produced by the rotomolding process. Using DSC and DMTA analysis, the values of three important parameters for the rotational molding process have been chosen:

- Oven temperatures: $280^{\circ} \mathrm{C}$

- Heating times: $15 \mathrm{~min}$

- Cooling rate: by blown air

In the macroscopic view, one can see that the good quality of the final pieces. Moreover, one can note that by increasing the percentage of NCB until $0.5 \%$ the microstructure doesn't change; nevertheless, for $1 \%$ and $3 \% \mathrm{NCBs}$, the porosity has obviously appeared. The tensile results of the samples indicate the overall behavior of pure PA-12 was influenced by adding NCBs. For $0.5 \%$ of NCBs maximum stress reaches around $55 \mathrm{MPa}$, however, for $3 \%$ of NCBs its value decreases to $20 \mathrm{MPa}$. The viscoelastic behavior of PA12 obeys the time-temperature equivalence principle. Moreover, using the Cole-Cole method, the theoretical curve fits perfectly on the experimental results, signifying the bi-parabolic model can accurately predict the viscoelastic behavior of PA-12.

\section{Compliance with ethical standards}

Conflict of interest There are no conflicts of interest to disclose. 


\section{References}

1. Greco A, Ferrari F, Buccoliero MG, Trono G (2019) Thermal and mechanical analysis of polyethylene homo-composites processed by rotational molding. Polymers (Basel) 11(3):1-16

2. R. A. M. Jaziri, "Reactive rotational molding process of PP/PA6 bilayer systems: experimental investigations," Int J Mater, no. 65, p. 21, 2013

3. S. Pivsa-Art, S. Thumsorn, S. Pavasupree, N. O-Charoen, and W. Pivsa-Art, "Effect of poly(butylene adipate-co-terephthalate) contents on crystallization and mechanical properties of polymer blends of poly(lactic acid) and poly[(butylene succinate)-coadipate]," Annu. Tech. Conf. - ANTEC, Conf Proc, vol. 3, pp. 2437-2441, 2013

4. Chang H, Li Q, Xu C, Li R, Wang H et al (2017) Wool powder: An efficient additive to improve mechanical and thermal properties of poly(propylene carbonate). Compos. Sci. Technol. 153:119-127

5. Vilakati GD, Hoek EMV, Mamba BB (2014) Probing the mechanical and thermal properties of polysulfone membranes modified with synthetic and natural polymer additives. Polym Test 34(202210):2014

6. Maskery I et al (2018) Insights into the mechanical properties of several triply periodic minimal surface lattice structures made by polymer additive manufacturing. Polymer (Guildf). 152:62-71

7. Ramezani, Dana H, Barbe F, Delbreilh L, Azzouna M, Guillet A, Breteau T (2019) Polymer additive manufacturing of ABS structure: influence of printing direction on mechanical properties. $\mathrm{J}$ Manuf Process 44:288-298

8. Kang E, Choi B, Park W, Kim I, Han D (2019) One step bulk modification of poly(L-lactic acid) composites with functional additives to improve mechanical and biological properties for cardiovascular implant applications. Colloids Surfaces B Biointerfaces 179:161-169

9. Li Z, Fan F, Xia Z, Li Q (2013) Effects of inorganic fillers on the shear viscosity and fire retardant performance of waterborne intumescent coatings. Prog Org Coatings 76(5):844-851

10. Seleem HEH (Jun. 2006) The effect of inorganic fillers on the mechanical and thermal properties of polyester. Polym Plast Technol Eng 45(5):585-590

11. Meincke DK, Ogliari AO, Ogliari FA (2016) Influence of different fillers on the properties of an experimental vinyl polysiloxane. Braz Oral Res 30(1):1-10

12. Tcharkhtchi JVA (2004) Structure-processability relationships during rotational moulding of plastics. Adv Eng Mater 6(12):983-992

13. Crawford R, Cramez MC, Oliveira MJ, Spence A (2002) The Importance of Monitoring Mold Pressure During Rotational Molding

14. “pericles_1548263444."

15. Gogos G (Feb. 2004) Bubble removal in rotational molding. Polym Eng Sci 44(2):388-394

16. Benzaine M, Tcharkhtchi A, Hafsaoui SL (2013) Thermal transfer simulation regarding the rotational moulding of polyamide 11 . $\mathrm{J}$ Therm Anal Calorim 112(1):285-292

17. Tcharkhtchi A, Perrot E, Chinesta F (2004) Simulation of thermal phenomena on the interphase molten polymer-powder polymer during rotational moulding,Plastics. InterPolymer Process XIX 3:296302

18. Sarrabi ATS, Boyer SAE, Lacrampe MF, Krawczak P (2013) Metallocene polypropylene crystallization kinetic during cooling in rotational molding thermal condition. J Appl Polym Sci 130(1):222-233

19. Bergamo L, Spa P (2019) "https://rotoworldmag.com/ measurement-and-control-of-pressure-inside-rotational-moulds/," Measurement and Control of Pressure Inside Rotational Moulds

20. K. R. Kent R (2016) Processing quality management, Qual. Manag. Plast. Process., pp. 293-336

21. Sari P, Thomas S, Spatenka P, Ghanam Z, Jenikova Z (2019) Effect of plasma modification of polyethylene on natural fibre composites prepared via rotational moulding. Compos Part B Eng 177:107344

22. Kulikov O, Hornung K, Wagner M (2009) Novel processing additives for rotational molding of polyethylene. Int Polym Process 24(5):452-462

23. Robert A, Tcharkhtchi MKA, Briot J, Crawford RG (2001) Rotomoulage du polyéthylène chargé Mica. matériaux Tech. 910:37-43

24. Arkema (2005) "Rilsan PA 11," Datasheet, pp. 1-32

25. Greco A, Maffezzoli A, Forleo S (2014) Sintering of PLLA powders for rotational molding. Thermochim Acta 582:59-67

26. Gomes FPC, Thompson MR (2018) Nondestructive evaluation of sintering and degradation for rotational molded polyethylene. Polym Degrad Stab 157:34-43

27. Nugent P (2011) 18 - rotational molding. William Andrew Publishing

28. Farzaneh S, Hafsaoui ATSL, Mahmoud R (2013) Study of polyamide 12 crystallization behavior within rotational molding process. Iran. Polym. J. 22(3):187

29. Nugent P (2017) 15 - rotational molding. William Andrew Publishing

30. Ebnesajjad S (2003) 9 - rotational molding and linings. William Andrew Publishing, Rotational Molding and Linings

31. Tcharkhtchi A, Rotomoulage de pièces en matière thermoplastique, Tech. l'ingénieur, vol. AM 3706, pp. 1-15

32. Fu JF, Yu WQ, Dong X, Chen LY, Jia HS, Shi LY, Zhong QD, Deng W (2013) Mechanical and tribological properties of natural rubber reinforced with carbon blacks and $\mathrm{A} 12 \mathrm{O} 3$ nanoparticles. Mater Des 49:336-346

33. Guo S et al (2019) Enhanced mechanical properties and electrical conductivity of graphene nanoplatelets/Cu composites by in situ formation of Mo2C nanoparticles. Mater. Sci. Eng. A 766(August): 138365

34. Ceran ÖB, Şimşek B, Doruk S, Uygunoğlu T, Şara ON (2019) Effects of dispersed and powdered silver nanoparticles on the mechanical, thermal, electrical and durability properties of cementitious composites. Constr Build Mater 222:152-167

35. Montazeri A, Pourshamsian K (2012) Viscoelastic properties and determination of free volume fraction of multi-walled carbon nanotube/epoxy composite using dynamic mechanical thermal analysis. Mater Des 36:408-414

36. Ferry JD (1970) Viscoelastic properties of polymers, 2nd edn. John Wiley, New York

37. Montazeri A (2013) The effect of functionalization on the viscoelastic behavior of multi-wall carbon nanotube/epoxy composites. Mater Des 45:510-517 